\title{
Towards Analysis and Optimization during Machining Hardened Steel AISI 4140 with Self- Propelled Rotary Tools
}

\author{
Waleed Ahmed ( $\nabla$ waleed.ahmed3@uoit.net ) \\ University of Ontario Institute of Technology \\ Hussien Hegab \\ University of Ontario Institute of Technology \\ Atef Mohany \\ Ontario Tech. University \\ Hossam Kishawy \\ University of Ontario Institute of Technology
}

\section{Research Article}

Keywords: Modeling, Machining, Optimization, Rotary tools

Posted Date: March 15th, 2021

DOI: https://doi.org/10.21203/rs.3.rs-286538/v1

License: @ (i) This work is licensed under a Creative Commons Attribution 4.0 International License.

Read Full License 


\section{Abstract}

It is necessary to improve the machinability of difficult-to-cut materials such as hardened steel, nickelbased alloys, and titanium alloys as these materials offer superior properties such as chemical stability, corrosion resistance, and high strength to weight ratio, making them indispensable for many applications. Machining with self-propelled rotary tools (SPRT) is considered as one of the promising techniques used to provide proper tool life even under dry conditions. In this work, an attempt has been performed to analyze, model, and optimize the machining process of AISI 4140 hardened steel using selfpropelled rotary tools. Experimental analysis has been offered to (a) compare the fixed and rotary tools performance, and (b) study the effect of the inclination angle on the surface quality and tool wear. Moreover, the current study implemented some artificial intelligence-based approaches (i.e., genetic programming and NSGA-II) to model and optimize the machining process of AISI 4140 hardened steel with self-propelled rotary tools. The feed rate, cutting velocity, and inclination angle are selected to be the design variables, while the tool wear, surface roughness, and material removal rate (MRR) are the studied outputs. Moreover, different weights have been assigned for the three studied outputs to offer different optimized solutions based on the designer interest (equal-weighted, finishing, and productivity scenarios). It should be stated that the findings of the current work offer valuable recommendations to select the optimized cutting conditions when machining hardened steel AISI 4140.

\section{Introduction}

Difficult-to-cut materials such as hardened steel, titanium alloys, ceramics are widely applied in many industrial fields, including aerospace, automotive, and biomedical [1]. The superior properties of these materials such as chemical stability, corrosion resistance, and high strength to weight ratio make them indispensable for many applications. However, machining of these materials is always a challenge due to their low thermal conductivity, which leads to a high concentration of the generated heat in the cutting zone and allows the temperature to hit severe levels [2]. This excessive concentrated heat affects machining performance and tool wear behavior. Besides, instantaneous damage to the machining surface and/or the insert could have occurred due to the high-temperature levels. Flood coolant is one of the widely used techniques to solve the concentrated heat problem by dissipating the generated heat to reduce the temperature. However, using the flood coolant technique has severe effects on the environment and the operators' health [3]. Besides, the employed coolant increases the operation cost by about $10 \%$ to $15 \%$, as discussed by Markesberry [4]. It was found that machining using self-propelled rotary tools can be a suitable approach, especially for difficult-to-cut materials, even under dry conditions $[5,6]$.

In the self-propelled rotary tools, the insert is a round disc that is allowed to freely rotate around its center. As a result of the tool motion, the whole circumference of the disc can be used as a cutting edge. Besides, the motion also allows each portion of the cutting edge to engage with the workpiece for a short time and disengage to cool down before cutting again, as shown in Fig. 1. Therefore, a self-cooling feature occurs when the tool rotates, which dissipates the generated heat and maintains acceptable temperature levels 
even under dry machining conditions. Moreover, the tool wear is distributed over the whole round edge instead of being concentrated at a single point as occurs in traditional machining. Thus, superior wear resistance was observed when machining with self-propelled rotary tools compared to traditional tools $[7,8]$.

Chen et al. [9] used self-propelled rotary tools made of carbide for machining SiCW/Al composite workpiece. The results showed that the rotary tools offer a dramatic increase in tool life compared to the traditional tools. Ezugwu [10] observed that the usage of the rotary tools provided better surface roughness reduced the machining temperature and increased the tool life compared to the conventional cases. A tool temperature model for machining using self-propelled rotary tools was developed by Kishawy et al. [11], and the results proved that lower cutting temperature occurs in the case of rotary tools compared to fixed tools. El-Mounayri et al. [12] conducted an experimental study to compare the machining characteristics (including surface quality, tool wear, and cutting forces) when utilizing selfpropelled rotary with conventional tools. The hardness of the workpiece material was 55RC workpiece, and coated carbide inserts were used. The results showed that SPRT provided better overall performance compared to traditional tools. Moreover, Kishawy et al. [13] developed an analytical model to predict the chip flow angle for the tube-end turning machining process of hardened steel using self-propelled rotary tools. This work was further developed, and another analytical model was provided to accurately predict the cutting forces when machining with self-propelled rotary tools [14]. The performance of machining hardened steel with self-propelled rotary tools was analyzed by Kishawy and Wilcox in terms of tool wear and chip morphology [15]. In addition to the analytical and experimental studies, Ahmed et al. [16] performed a numerical study to model the machining with rotary tools, and 3-D distribution of the tool's temperature was presented.

On the other hand, multi-objective optimization using non-sorted genetic algorithm (NSGA-II) was employed in Abbas et al. study [17] to optimize the machining performance and sustainability aspects using different cooling techniques when machining AISI 1045 steel. An integrated approach between the genetic algorithm and neural network was used by Sangwan et al. [18] to optimize the machining variables to minimize the surface roughness when machining Ti-6al-4v. Pawar et al. [19] employed the artificial bee colony algorithm to perform multi-objective optimization for the wire-electric discharge process. The tool wear, surface roughness, and productivity aspects were considered as machining outputs. Dabade et al. [20] utilized self-propelled rotary tools for the face milling process. Optimization was employed to study the effect of the machining variables on the output responses include chip crosssurface area and surface roughness. The inclination angle was the most significant variable that affects the machining outputs. Besides, Hao et al. [21] used the artificial neural network (ANN) technique to predict the cutting force components when machining low carbon steel. Cutting velocity, feed rate, tool inclination angle, and depth of cut were considered as input variables.

There are minimal studies in the open literature that implemented the multi-objective optimization approach in the area of machining with self-propelled rotary tools [22,23]. In addition, few models have been performed (either analytical or artificial intelligence-based models) to model the wear behavior and 
surface integrity when machining with rotary tools and the majority of the developed models are focused on the cutting forces. Firstly, in this work, experimental analysis has been offered to (a) compare between the fixed and rotary tools performance and (b) study the effect of the inclination angle on the surface quality and tool wear. Secondly, the current study implemented some artificial intelligence-based approaches (i.e., genetic programming and NSGA-II) to model and optimize the machining process of hardened steel AISI 4140 with self-propelled rotary tools. The feed rate, cutting velocity, and inclination angle are selected to be the design variables, while the tool wear, surface roughness, and material removal rate (MRR) are the studied outputs. Moreover, different weights have been assigned for the three studied outputs to offer different optimized solutions based on the designer interest (equal-weighted, finishing, and productivity scenarios). Fig. 2 shows the flow chart of the current work methodology.

\section{Experimentation And Analysis}

In the current study, different cutting tests were carried out to investigate and analyze the effect of the cutting conditions on the machining performance when using self-propelled rotary tools. The workpiece material was hardened steel AISI 4140 ( $46 \pm 2 \mathrm{HRC}$ ). A tube shape workpiece was used to achieve homogeneous properties during the heat treatment process. The outer diameter of the workpiece was 100 $\mathrm{mm}$, while the inner diameter was $50 \mathrm{~mm}$, as shown in Fig. 3. Table 1 shows the chemical composition, thermal, and mechanical properties of AISI 4140 steel. The feed rate, cutting speed, and inclination angle were selected as design variables. The depth of cut was $0.2 \mathrm{~mm}$, while the cutting length was $100 \mathrm{~mm}$. A carbide round insert was used, and its outer diameter was $27 \mathrm{~mm}$. The rake angle was $-5^{\circ}$, while the clearance angle was $5^{\circ}$. Fig. 4 shows the experimental setup of the current study.

Table 1. Chemical composite, thermal, and mechanical properties of AISI 4140

$$
\begin{aligned}
& \text { Chemical composition (wt.\%): C: } 0.38 \%-0.43 \% \text {, Sl: } 0.15 \%-0.3 \%, \mathrm{Mn}: 0.7 \%-1 \% \text {, } \\
& \qquad \text { Cr: } 0.8 \%-1.1 \%, \mathrm{Mo:} 0.15 \%-0.25 \%, \mathrm{Fe}: 96.75 \%-97.84 \\
& \text { Density: } 7850 \mathrm{Kg} / \mathrm{m}^{3} \\
& \text { Young's modulus (at } 25^{\circ} \mathrm{C} \text { ): } 198 \mathrm{GPa} \\
& \text { Poisson's ratio (at } 25^{\circ} \mathrm{C} \text { ): } 0.3 \\
& \text { Tensile strength: } 729.5 \mathrm{MPa} \\
& \text { Yield strength: } 379.2 \mathrm{MPa} \\
& \text { Specific Heat (at } 25^{\circ} \mathrm{C} \text { ): } 470 \mathrm{~J} / \mathrm{kg}^{\circ} \mathrm{C} \\
& \text { Thermal Conductivity (at } 25^{\circ} \mathrm{C} \text { ): } 42.7 \mathrm{~W} / \mathrm{m}^{\circ} \mathrm{C}
\end{aligned}
$$$$
\text { Cr: } 0.8 \%-1.1 \% \text {, Mo: 0.15\%-0.25\%, Fe: } 96.75 \%-97.84 \%
$$

The average surface roughness was used to evaluate the machined surface quality. The average surface roughness was measured using Mitutoyo (SJ.201) portable surface roughness at a cut-off length of $2.5 \mathrm{~mm}$. The surface roughness was measured at three different locations, and the average value was 
calculated and used for the analysis. Mitutoya toolmaker's microscope (TM-A505B) was used to measure the average flank wear of the insert after each run. The flank tool wear was measured at four different locations on the circular flank face of the insert, and the average value is obtained and used in the analysis. Fig. 5 shows a flow chart for the experimental procedures.

Taguchi's approach was utilized in the current study to conduct a minimum number of experiments. Three design variables with four levels each were used in the present study. The selected design variables were inclination angle (i), feed rate $(f)$, and cutting speed $(V)$. The design variable and the assigned level for each variable are presented in Table 2. As there are three design variables with four levels each (i.e., $4^{3}$ ), the full L640A orthogonal array should be used. However, a fractional factorial, L160A orthogonal array was employed to save cost and time [24]. Table 3 shows the 16 experiments of the current study.

Table 2. The levels assignment to the independent design variables

\begin{tabular}{|lllll|}
\hline Design variables & Level 1 & Level 2 & Level 3 & Level 4 \\
\hline A:i $\left(^{\circ}\right)$ & 5 & 10 & 15 & 20 \\
\hline B:f $(\mathrm{mm} / \mathrm{rev})$ & 0.1 & 0.15 & 0.2 & 0.25 \\
\hline C:V $(\mathrm{m} / \mathrm{min})$ & 70 & 127 & 167 & 240 \\
\hline
\end{tabular}

Table 3. The design of experiments for the machining runs 


\begin{tabular}{|llll|}
\hline Test \# & Inclination angle levels & Feed rate levels & Cutting speed levels \\
\hline 1 & 1 & 1 & 1 \\
\hline 2 & 1 & 2 & 2 \\
\hline 3 & 1 & 3 & 3 \\
\hline 4 & 1 & 4 & 4 \\
\hline 5 & 2 & 1 & 2 \\
\hline 6 & 2 & 2 & 1 \\
\hline 7 & 2 & 3 & 4 \\
\hline 8 & 2 & 4 & 3 \\
\hline 9 & 3 & 1 & 3 \\
\hline 10 & 3 & 2 & 4 \\
\hline 11 & 3 & 3 & 1 \\
\hline 12 & 3 & 4 & 2 \\
\hline 13 & 4 & 1 & 4 \\
\hline 14 & 4 & 2 & 3 \\
\hline 15 & 4 & 3 & 2 \\
\hline 16 & 4 & 4 & 1 \\
\hline
\end{tabular}

Table 4 shows the results of the average flank tool wear and average surface roughness during dry machining with self-propelled rotary tools. The minimum flank tool wear is observed at test 6 , where the cutting speed was $70 \mathrm{~m} / \mathrm{min}$, the inclination angle was $10^{\circ}$, and the feed rate was $0.15 \mathrm{~mm} / \mathrm{rev}$. Besides, test 14 showed the highest flank tool wear, where the cutting speed was $167 \mathrm{~m} / \mathrm{min}$, the inclination angle was $20^{\circ}$, and the feed rate was $0.15 \mathrm{~mm} / \mathrm{rev}$. In general, the results showed that reducing the cutting speed leads to low flank wear, as expected. Unlike conventional cutting, increasing the feed rate leads to a decrease in the flank tool wear. That could be attributed to the fact that the cutting process becomes more stable at a high feed rate as a continuous chip was noticed.

Regarding the average surface roughness, the results revealed that the variation of the cutting conditions has a corresponding effect on the surface roughness. The optimal surface roughness was obtained at test 13 , where the cutting speed was $240 \mathrm{~m} / \mathrm{min}$, the inclination angle was $20^{\circ}$, and the feed rate was 0.1 $\mathrm{mm} / \mathrm{rev}$. In general, the surface roughness values were relatively low compared to the conventional cutting processes. That could be attributed to the large radius of the round insert compared to the nose radius of traditional tools. Increasing the cutting velocity lead to a reduction in the surface roughness 
value, as expected. Besides, increasing the feed rate leaded to deterioration of the machined surface due to the increase of the chip load.

Table 4. Average surface roughness and tool wear results

\begin{tabular}{|llllll|}
\hline $\begin{array}{l}\text { Test } \\
\#\end{array}$ & $\mathrm{i}\left({ }^{\circ}\right)$ & $\mathrm{f}(\mathrm{mm} / \mathrm{rev})$ & $\mathrm{V}(\mathrm{m} / \mathrm{min})$ & $\mathrm{VB}(\mu \mathrm{m})$ & $\mathrm{Ra}(\mu \mathrm{m})$ \\
1 & 5 & 0.1 & 70 & 16 & 0.83 \\
2 & 5 & 0.15 & 127 & 38 & 1.08 \\
\hline 3 & 5 & 0.2 & 167 & 20 & 0.78 \\
\hline 4 & 5 & 0.25 & 240 & 22 & 0.95 \\
\hline 5 & 10 & 0.1 & 127 & 61 & 1.00 \\
\hline 6 & 10 & 0.15 & 70 & 3 & 1.13 \\
\hline 7 & 10 & 0.2 & 240 & 59 & 0.84 \\
\hline 8 & 10 & 0.25 & 167 & 14 & 0.90 \\
9 & 15 & 0.1 & 167 & 51 & 1.18 \\
\hline 10 & 15 & 0.15 & 240 & 25 & 0.93 \\
\hline 11 & 15 & 0.2 & 70 & 5 & 1.17 \\
\hline 12 & 15 & 0.25 & 127 & 40 & 1.48 \\
\hline 13 & 20 & 0.1 & 240 & 12 & 0.56 \\
\hline 14 & 20 & 0.15 & 167 & 71 & 0.94 \\
\hline 15 & 20 & 0.2 & 127 & 51 & 1.11 \\
\hline 16 & 20 & 0.25 & 70 & 4 & 1.83 \\
\hline & & & & & \\
\hline
\end{tabular}

A comparison between the fixed and rotary tools was performed to study the effect of the tool motion on the studied machining responses. Fig. 6 shows the tool wear results for fixed and rotary tools at the best and worst conditions (i.e., test 6 and test 14). The wear of the rotary tool was reduced by $37 \%$ at test 14 (where the maximum tool wear occurred) compared to the fixed tool. Besides, at test 6 , the tool wear of the rotary tool was reduced by $22 \%$ compared to the fixed tool. That could be attributed to the benefits of the tool rotational motion. Fig. 7 shows a schematic of machining using a self-propelled rotary tool. Part of the generated heat at the secondary shear zone $\left(\mathrm{Q}_{\mathrm{sz}}\right)$ goes to the cutting tool $\left(\mathrm{Q}_{\text {tool }}\right)$. A portion of this heat is dissipated by conduction $\left(Q_{\text {cond }}\right)$, and the large portion is carried away from the cutting zone by the tool motion $\left(\mathrm{Q}_{\text {motion }}\right)$.Therefore, as a result of the tool motion, every portion of the cutting edge will have a chance to cool down during the disengagement period before engaging again with the workpiece. 
That will prevent the tool from any expected thermal damages by maintaining the tool temperature within acceptable limits even under dry machining as a result of the self-cooling feature of the rotary tools. In addition, the tool motion allows the tool wear to be distributed over the whole round edge instead of being concentrated at a single point, as occurs in the conventional tools, which dramatically increases the tool life.

Fig. 8 shows surface roughness results for fixed and rotary tools at the best and worst conditions (i.e., test 13 and test 16$)$. Better surface roughness was provided by the fixed tool, especially at the worst condition (i.e., test 16), where the surface roughness of the rotary insert achieved $1.83 \mu \mathrm{m}$. That can be due to different possible factors include machining stability, which is significantly affected by the dynamic nature of the rotary tool. Besides, the surface roughness is also affected by the generated marks in the direction of the relative cutting velocity as a result of the tool motion, as discussed in previous work [5].

To study the effect of the inclination angle on the tool wear and the surface quality, a comparison was performed between two cutting tests under certain conditions of cutting speed and feed rate (i.e., $v=167$ $\mathrm{m} / \mathrm{min}$ and $\mathrm{f}=0.15 \mathrm{~mm} / \mathrm{rev}$ ) with two different inclination angles of $5^{\circ}$ and $20^{\circ}$, as shown in Fig. 9 . It was observed that when using a low inclination angle (i.e., $5^{\circ}$ ), the chips were collided and pushed into the workpiece surface, as shown in Fig. 9(b). Afterward, the cutting edge crushes the adhered chips, which increases the tool wear, as can be seen in Fig. 9(d). On the other hand, no chips adhesion was observed in the machined surface at $20^{\circ}$ inclination angle (see Fig. 9(a)), and accordingly, lower tool wear was obtained compared to the case of $5^{\circ}$ inclination angle (see Fig. 9(c)). That can be attributed to the increase in the chip flow angle based on the oblique cutting principles, as confirmed by Yamamoto et al. [25].

\section{Modeling Of The Machining Characteristics}

In this section, genetic programming (GP) was used to empirically model the surface roughness and tool wear. Genetic programming is considered one of the most artificial intelligence effective techniques, and it is used in different engineering applications [26]. In genetic programming, each program is built of a tree structure of terminals and functions (i.e., genotype). The terminals (i.e., leaves) are the inputs to the program, and the used functions of the GP program include mathematical functions, programming functions, and arithmetic operations. Every generated model is presented as a chromosome, and the fitness function is used to evaluate each chromosome. The fitness function measures the error between the model output and the input training data. Genetic operators include mutation, and crossover factors are then utilized to generate new chromosomes. In the open literature, many studies used genetic programming to model the cutting processes [27-29]. In the current study, the Eureqa software was used to develop models of the surface roughness and tool wear, as shown in equation 1 and equation 2 , respectively. 


$$
\begin{gathered}
\mathrm{Ra}=0.0066 * \mathrm{i}^{2}+42.91 * \mathrm{i} * \mathrm{f}^{4}-0.07 * \mathrm{i}-2.20 \mathrm{e}^{-9} * \mathrm{~V} * \mathrm{i}^{5} \\
-10.9 * \mathrm{i} * \mathrm{f}^{3}+1.12
\end{gathered}
$$

$$
\begin{aligned}
\mathrm{VB}= & 387.22+\frac{8.32}{\mathrm{f}}+16.53 * \mathrm{i} * \mathrm{f}+0.03 * \mathrm{f} * \mathrm{~V}^{2} \\
& -\frac{21799.6+16.53 * \mathrm{i}^{2} * \mathrm{f}^{2}}{\mathrm{~V}}-2.31 * \mathrm{~V}-50.67 * \mathrm{~V} * \mathrm{f}^{3}
\end{aligned}
$$

Fig. 10 and Fig. 11 show a comparison between the experimental and predicted results for flank tool wear and average surface roughness, respectively. The surface roughness $(\mathrm{Ra})$ model showed average model accuracy of $94.33 \%$ with 0.89 goodness of fit $\left(R^{2}\right)$ and 3.99 mean absolute error. Besides, the average model accuracy of $87.44 \%$ was achieved for the tool wear model with 0.88 goodness of fit $\left(R^{2}\right)$ and 4.02 mean absolute error.

\section{Multi-objective Optimization}

The non-dominated sorting genetic algorithm (NSGA-II) is used in the current study to perform multiobjective optimization of the generated models. The NSGA-II is one of the popular multi-objective optimization techniques as it utilized special features such as fast non-dominated method, fast crowded estimation of distances approach, and simple operator to perform a crowded comparison to find the optimal Pareto-front solutions [30]. The genetic algorithm evolutionary operators such as crossover and mutation are utilized in the NSGA-II algorithm. The general steps of the NSGA-II can be summarized as follows [31]:

- Select the size of the population based on the constraints and their range.

- Perform non-dominated sort for the initialized populations

- Assign crowding distance values for the population of individuals

- Select the individuals based on the rank and the crowding distance

- Apply the genetic algorithm crossover and mutation operators

- Recombine and select an individual for the next generation until the population size exceeds the current size

Three machining objective functions were considered in the optimization process; tool wear, surface roughness, and material removal rate. The problem constraints, according to the current experimental plan, are as follows: 


\section{$\left\{\begin{aligned} 5^{\circ} & \leq \mathrm{i} \leq 20^{\circ} \\ 0.1 \mathrm{~mm} / \mathrm{rev} & \leq \mathrm{f} \leq 0.25 \mathrm{~mm} / \mathrm{rev} \\ 70 \mathrm{~m} / \mathrm{min} & \leq \mathrm{V} \leq 240 \mathrm{~m} / \mathrm{min}\end{aligned}\right.$}

A sensitivity analysis was performed to select the optimized parameters used for NSGA-II. Hypervolume Indicator was calculated to evaluate the performance of the Pareto-front solutions set. This indicator is used to measure the convergence and the diversity of Pareto-front solutions [32]. The hypervolume indicator follows the higher-better criteria, which means the optimized solution can be found at the highest hypervolume indicators. In the current study, the hypervolume indicator was calculated at three different values of crossover (i.e., $0.6,0.7$, and 0.8 ) and three values of mutation (i.e., $0.005,0.01$, and 0.015). Fig. 12 shows that the highest hypervolume indicator of $7.3 \%$ was obtained at a mutation factor of 0.01 , and a crossover rate of 0.7 , which was used in the current optimization algorithm. The population size of 400 was selected, and the solver was allowed to proceed until the function tolerance of $10^{-4}$ was achieved.

The binary chromosome was utilized to express the individuals (i.e., solutions), as can be seen in Fig. 13(a). The crossover, selection, crossover, and mutation operations are conducted to offer a new offsprings population for the next generation. In terms of the selection, the binary tournament operation was utilized to determine the individuals in the first generation for the mating pool. Then, the crowdedcomparison operator has used for the selection operation in the next generations based on the rank and the crowded-distance, as discussed in previous work [30]. Then, the selected solutions in the mating pool are used for the crossover and mutation process. Two-point crossover is randomly adopted to provide offspring pairs through exchanging parts of their parents, as provided in Fig. 13(b). In the single point mutation process, offspring is clarified by changing 1-gen in the original solution to maintain the diversity in the population, as provided in Fig. 13(c). These steps are repeated until reaching the stopping criterion. In the end, the set of non-dominated solutions are considered as the highest-ranked front after achieving the stop criterion.

Fig. 14 shows the Pareto-front solutions for the three objectives functions. The Pareto-front solution is distributed into two groups, group 1 and group 2. For the first group, it can be noticed that the dominant relationship between the tool wear and the material removal rate is an interdependent based-relation. That could be attributed to the high cutting velocity, which associates the high material removal rate. Besides, there is a reduction in the surface roughness values when decreasing the inclination angle and the cutting speed. That is because the surface roughness when machining with self-propelled rotary tools mainly depends on the machining stability due to the dynamic nature of the process. The tool rotational speed is directly affected by the cutting velocity and the inclination angle, as seen in equation 3 [33]:

$V_{r}=V \sin i$

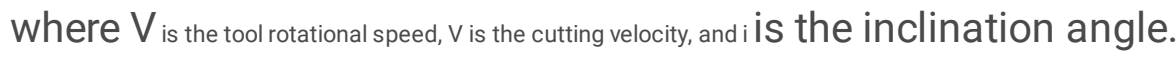


Therefore, the low inclination angle and cutting velocity lead to the slow rotational speed of the cutting insert, which increases the machining stability and produces better surface quality. For the second group, the dominant

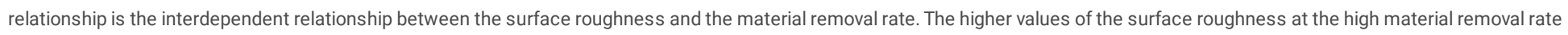
are due to the large value of the cutting velocity, which increases the rotational speed of the insert (see equation 3 ) and accordingly reduces the machining stability.

\section{Optimized Scenarios}

This section provides a new approach to optimize Pareto-front solutions based on different machining scenarios. Three different machining scenarios were investigated; equal-weighted, productivity, and finishing. Different weighting factors were assigned to each scenario to evaluate the output responses. Table 5 presents the scenarios used and the weighting factors for each scenario. The multi-objective optimization NSGA-II provides a number of Pareto-front solutions, and to choose the best optimal solution for a certain scenario (e.g., finishing or productivity), normalized Pareto-front solutions are based on each scenario were obtained. Afterward, the highest normalized solution in each scenario was considered. The highest optimized solution means that the selected solution achieves the best balance between all the output responses within each studied scenario.

Table 5. The weighting factors for the machining scenarios

\begin{tabular}{|lcc|}
\hline & Machining Outputs \\
Scenario & Ra $\quad$ VB & MRR \\
& & \\
\hline
\end{tabular}

\begin{tabular}{|llll|}
\hline (A): Equal-weighted & $33.33 \%$ & $33.33 \%$ & $33.33 \%$ \\
\hline (B): Productivity & $10 \%$ & $30 \%$ & $60 \%$ \\
\hline (C): Finishing & $70 \%$ & $20 \%$ & $10 \%$ \\
\hline
\end{tabular}

Table 6 shows the result of the normalized optimal solutions for the three studied scenarios. The optimal cutting conditions for the productivity scenario were obtained at the highest cutting velocity and feed rate (i.e., $V=240 \mathrm{~m} / \mathrm{min}$ and $\mathrm{f}=0.25 \mathrm{~mm} / \mathrm{rev}$ ), as expected, and at an inclination angle of $7^{\circ}$. While the optimum conditions for the finishing scenario were found at a cutting velocity of $235 \mathrm{~m} / \mathrm{min}$, a feed rate of 0.19 $\mathrm{mm} / \mathrm{rev}$, and an inclination angle of $19^{\circ}$. Moreover, the optimal conditions for the equal-weighted scenario) were found at a cutting velocity of $98 \mathrm{~m} / \mathrm{min}$, a feed rate of $0.23 \mathrm{~mm} / \mathrm{rev}$, and an inclination angle of $7^{\circ}$.

To validate the effectiveness of the three studied scenarios, confirmation experimental tests have been conducted, and the results showed good agreement with the predicted values, as can be seen in Fig. 14 . For the flank wear results, the maximum deviation was about $8 \mu \mathrm{m}$ at the finishing scenario. Regarding the surface roughness results, the maximum deviation was about $0.17 \mu \mathrm{m}$ for the equal-weighted case. 
Table 6. A summary of the optimal solutions for the studied scenarios

\begin{tabular}{|lllll|}
\hline \multicolumn{5}{|c|}{ Machining Outputs } \\
Scenario & a & VB & \multicolumn{2}{l|}{ MRR } \\
& $(\mu \mathrm{m})$ & $(\mu \mathrm{m})$ & $\left(\mathrm{mm}^{3} / \mathrm{min}\right)$ \\
\hline & & & & \\
\hline (A): Equal-weighted & 0.87 & 2.42 & 4580 \\
\hline (B): Productivity & 0.92 & 32.56 & 11851 \\
\hline (C): Finishing & 0.38 & 79.93 & 9156 \\
\hline
\end{tabular}

\section{Conclusions And Future Work}

This work offers an attempt to analyze, model, and optimize the machining of AISI 4140 hardened steel with SPRT. The main findings obtained in this study have been summarized as follows:

- Using a self-propelled rotary tool reduced the flank tool wear by $37 \%$ and $22 \%$ at the worst and best cutting conditions, respectively, compared to the fixed tool;

- Unlike conventional cutting, increasing the feed rate leaded to a decrease in the flank tool wear;

- A comparison between the self-propelled rotary tool and the fixed tool shows that the fixed tool provided better surface roughness;

- A comparison between two cutting tests with different inclination angles shows that there was no chips adhesion observed in the machined surface at $20^{\circ}$ inclination angle, and accordingly, lower tool wear was obtained compared to the case of $5^{\circ}$ inclination angle;

- In general, the surface roughness values are relatively low in round tools compared to the conventional cutting tools; however, better surface roughness was observed for fixed case compared to the rotary case;

- Based on the optimized scenarios of multi-objective optimization (NSGA-II), the optimal cutting variable levels for the equal-weighted scenario were found at a cutting velocity of $98 \mathrm{~m} / \mathrm{min}$, a feed rate of $0.23 \mathrm{~mm} / \mathrm{rev}$, and an inclination angle of $7^{\circ}$. Besides, the optimal cutting conditions for the productivity scenario were obtained at the highest cutting velocity and feed rate (i.e., $V=240 \mathrm{~m} / \mathrm{min}$ and $\mathrm{f}=0.25 \mathrm{~mm} / \mathrm{rev}$ ), and an inclination angle of $7^{\circ}$. While the optimum conditions for the finishing scenario were found at a cutting velocity of $235 \mathrm{~m} / \mathrm{min}$, a feed rate of $0.19 \mathrm{~mm} / \mathrm{rev}$, and an inclination angle of $19^{\circ}$.

- To validate the effectiveness of the three studied scenarios, confirmation experimental tests have been conducted, and the results showed a good agreement with the predicted values. 
It should be stated that the findings of the current work offer valuable recommendations to select the optimized cutting conditions when machining hardened steel AISI 4140. In terms of future work, an indepth analytical model is needed to fully understand the chip formation mechanisms for the machining process with self-propelled rotary tools.

\section{Declarations}

Acknowledgments: The authors acknowledge the support of the Natural Sciences and Engineering Research Council of Canada (NSERC).

Ethical approval: The authors confirm that this work does not contain any studies with human participants performed by any of the authors.

Consent to publish: The author grants the publisher the sole and exclusive license of the full copyright in the contribution, which license the publisher hereby accepts.

Funding: This study was funded by the Natural Sciences and Engineering Research Council of Canada (NSERC).

Competing interests: The authors declare and confirm no conflict of interest.

Availability of data and materials: All data generated or analyzed during this study are included in this published article.

Consent to participate: Not applicable.

\section{References}

1. Kishawy HA, Hosseini A (2019) Machining difficult-to-cut materials. Mater Form Mach Tribol

2. El-Wardany T, Mohammed E, Elbestawi M (1996) Cutting temperature of ceramic tools in high speed machining of difficult-to-cut materials. International Journal of Machine Tools and Manufacture 36 (5):611-634

3. Shokrani A, Dhokia V, Newman ST (2012) Environmentally conscious machining of difficult-tomachine materials with regard to cutting fluids. International Journal of machine Tools and manufacture 57:83-101

4. Marksberry P (2007) Micro-flood (MF) technology for sustainable manufacturing operations that are coolant less and occupationally friendly. Journal of Cleaner Production 15 (10):958-971

5. Kishawy H, Becze C, McIntosh D (2004) Tool performance and attainable surface quality during the machining of aerospace alloys using self-propelled rotary tools. Journal of materials processing technology 152 (3):266-271

6. Sasahara H, Kato A, Nakajima H, Yamamoto H, Muraki T, Tsutsumi M (2008) High-speed rotary cutting of difficult-to-cut materials on multitasking lathe. International journal of machine tools and 
manufacture 48 (7-8):841-850

7. Kishawy H, Wilcox J (2003) Tool wear and chip formation during hard turning with self-propelled rotary tools. International Journal of Machine Tools and Manufacture 43 (4):433-439

8. Kishawy H, Pang L, Balazinski M (2011) Modeling of tool wear during hard turning with selfpropelled rotary tools. International Journal of Mechanical Sciences 53 (11):1015-1021

9. Chen P, Hoshi T (1992) High-Performance Machining of SiC Whisker-Reinforced Aluminium Composite by Self-Propelled Rotary Tools. CIRP Annals 41 (1):59-62

10. Ezugwu EO (2007) Improvements in the machining of aero-engine alloys using self-propelled rotary tooling technique. Journal of Materials Processing Technology 185 (1):60-71

11. Kishawy $\mathrm{H}$, Gerber A A model for the tool temperature during machining with a rotary tool. In: International mechanical engineering congress and exposition symposium on fundamental issues in machining, 2001. pp 1-10

12. El-Mounayri H, Razak AL, Kessler M Investigating Turning of Hard-to-Cut Material Using SelfPropelled Rotary Tool. In: ASME 2011 International Manufacturing Science and Engineering Conference, Corvallis, Oregon, USA, 13-17 June 2011. ASME, pp 331-338

13. Kishawy H, Li L, El-Wahab A (2006) Prediction of chip flow direction during machining with selfpropelled rotary tools. International Journal of Machine Tools and Manufacture 46 (12-13):16801688

14. Li L, Kishawy H (2006) A model for cutting forces generated during machining with self-propelled rotary tools. International Journal of Machine Tools and Manufacture 46 (12-13):1388-1394

15. Kishawy HA, Wilcox $\mathrm{J}$ (2003) Tool wear and chip formation during hard turning with self-propelled rotary tools. International Journal of Machine Tools and Manufacture 43 (4):433-439

16. Dessoly V, Melkote SN, Lescalier C (2004) Modeling and verification of cutting tool temperatures in rotary tool turning of hardened steel. International Journal of Machine Tools and Manufacture 44 (14):1463-1470

17. Abbas AT, Benyahia F, El Rayes MM, Pruncu C, Taha MA, Hegab H (2019) Towards optimization of machining performance and sustainability aspects when turning AISI 1045 Steel under different cooling and lubrication strategies. Materials 12 (18):3023

18. Sangwan KS, Saxena S, Kant G (2015) Optimization of machining parameters to minimize surface roughness using integrated ANN-GA approach. Procedia Cirp 29:305-310

19. Pawar P, Khalkar M (2020) Multi-objective Optimization of Wire-Electric Discharge Machining Process Using Multi-objective Artificial Bee Colony Algorithm. In: Advanced Engineering Optimization Through Intelligent Techniques. Springer, pp 39-46

20. Dabade UA, Joshi S, Ramakrishnan N (2003) Analysis of surface roughness and chip cross-sectional area while machining with self-propelled round inserts milling cutter. Journal of Materials Processing Technology 132 (1-3):305-312 
21. Hao W, Zhu X, Li X, Turyagyenda G (2006) Prediction of cutting force for self-propelled rotary tool using artificial neural networks. Journal of Materials Processing Technology 180 (1):23-29.

22. Rao TB, Krishna AG, Katta RK, Krishna KR (2015) Modeling and multi-response optimization of machining performance while turning hardened steel with self-propelled rotary tool. Advances in Manufacturing 3 (1):84-95

23. Gurgen S, Sofuoglu MA, Cakir FH, Orak S, Kushan MC (2015) Multi response optimization of turning operation with self-propelled rotary tool. Procedia-Social and Behavioral Sciences 195:2592-2600

24. Gangil M, Pradhan M (2017) Modeling and optimization of electrical discharge machining process using RSM: a review. Materials Today: Proceedings 4 (2):1752-1761

25. Yamamoto H, SATAKE K, NARITA T, SASAHARA H, TSUTSUMI M, MURAKI T B29 Thermal Behavior and Chip Formation on Rotary Cutting of Difficult-to-cut Materials Utilizing Multi Tasking Lathe and MQL (Advanced machining technology). In: Proceedings of International Conference on Leading Edge Manufacturing in 21 st century: LEM21 2009.5, 2009. The Japan Society of Mechanical Engineers, pp 661-666

26. Banzhaf W, Nordin P, Keller RE, Francone FD (1998) Genetic programming. Springer,

27. Brezocnik M, Kovacic M, Ficko M (2004) Prediction of surface roughness with genetic programming. Journal of materials processing technology 157:28-36

28. Kök M, Kanca E, Eyercioğlu Ö (2011) Prediction of surface roughness in abrasive waterjet machining of particle reinforced MMCs using genetic expression programming. The International Journal of Advanced Manufacturing Technology 55 (9):955-968

29. Garg A, Tai K Review of genetic programming in modeling of machining processes. In: 2012 Proceedings of International Conference on Modelling, Identification and Control, 2012. leee, pp 653658

30. Deb K, Pratap A, Agarwal S, Meyarivan T (2002) A fast and elitist multiobjective genetic algorithm: NSGA-II. IEEE transactions on evolutionary computation 6 (2):182-197

31. Chen J Multi-objective optimization of cutting parameters with improved NSGA-II. In: 2009 International Conference on Management and Service Science, 2009. IEEE, pp 1-4

32. Zitzler E (1999) Evolutionary algorithms for multiobjective optimization: Methods and applications, vol 63. Ithaca: Shaker

33. Armarego E, Katta R (1997) Predictive cutting model for forces and power in self-propelled rotary tool turning operations. CiRP Annals 46 (1):19-24

\section{Figures}




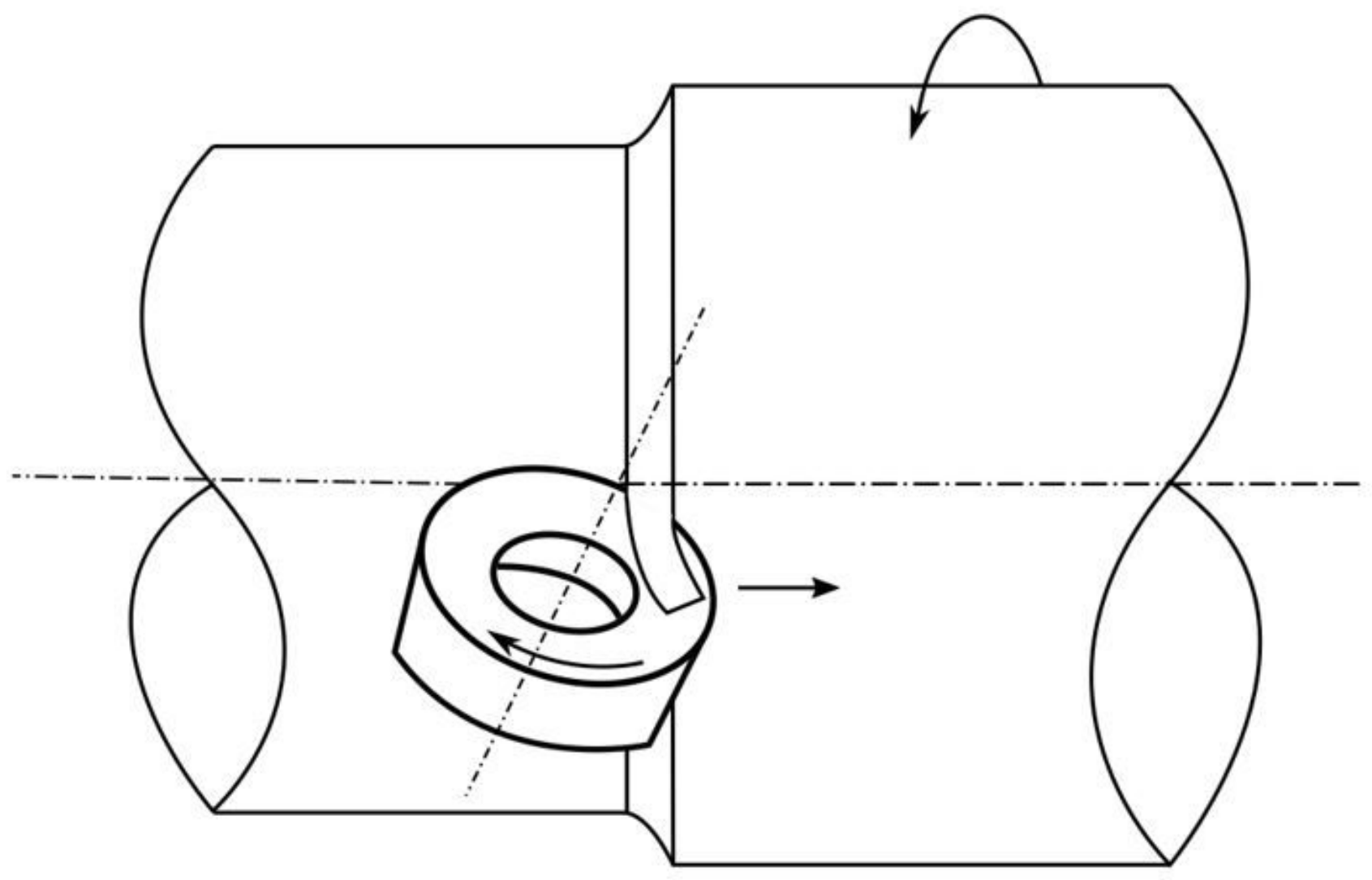

Figure 1

Machining with self-propelled rotary tools 


\section{Objectives of the work}

- Investigate the effectiveness of machining process using SPRT

- Provide optimal cutting conditions to achieve lowest tool wear, maximum material removal rate, and best surface quality

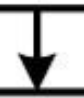

\section{Experimentation}

- Bar turning of hardened-steel AISI 4140 using SPRT under dry conditions

- Compare the machining performance for the rotary and fixed tools at the best and worst conditions

- Study the effect of the inclination angle on the surface quality and tool wear

\section{Modeling of the machining process}

- Use the genetic programming (GP) to model the output responses

\section{Multi-objectives optimization}

- Use the non-dominated sorting genetic algorithm (NSGA-II) to find the pareto-front solutions and the crossponding cutting conditions

\section{Optimized scenarios}

- Optimize the pareto-front solution based on different machining scenarios

\section{Figure 2}

Flow chart for the research methodology 


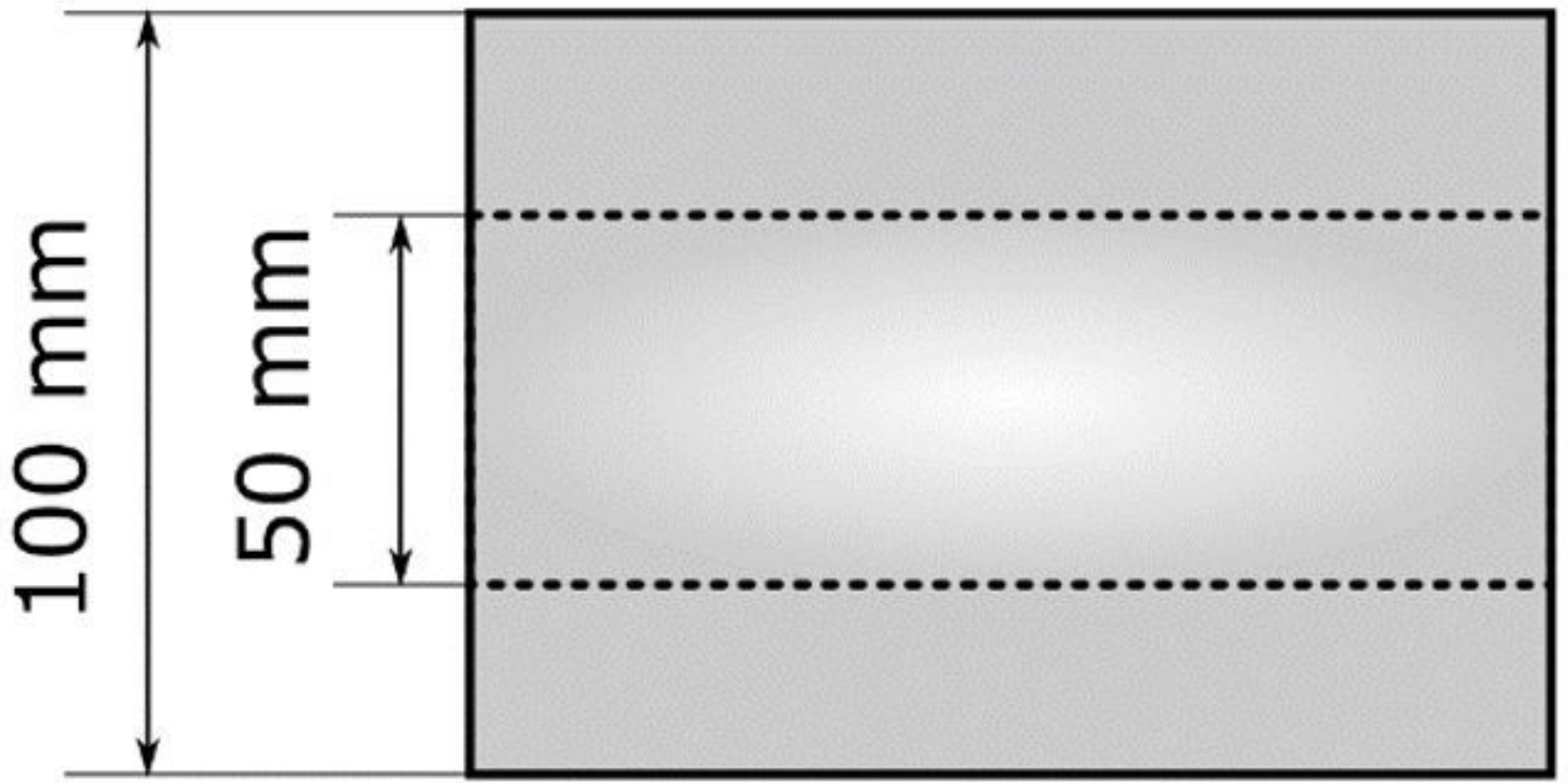

Figure 3

Tube shape workpiece 


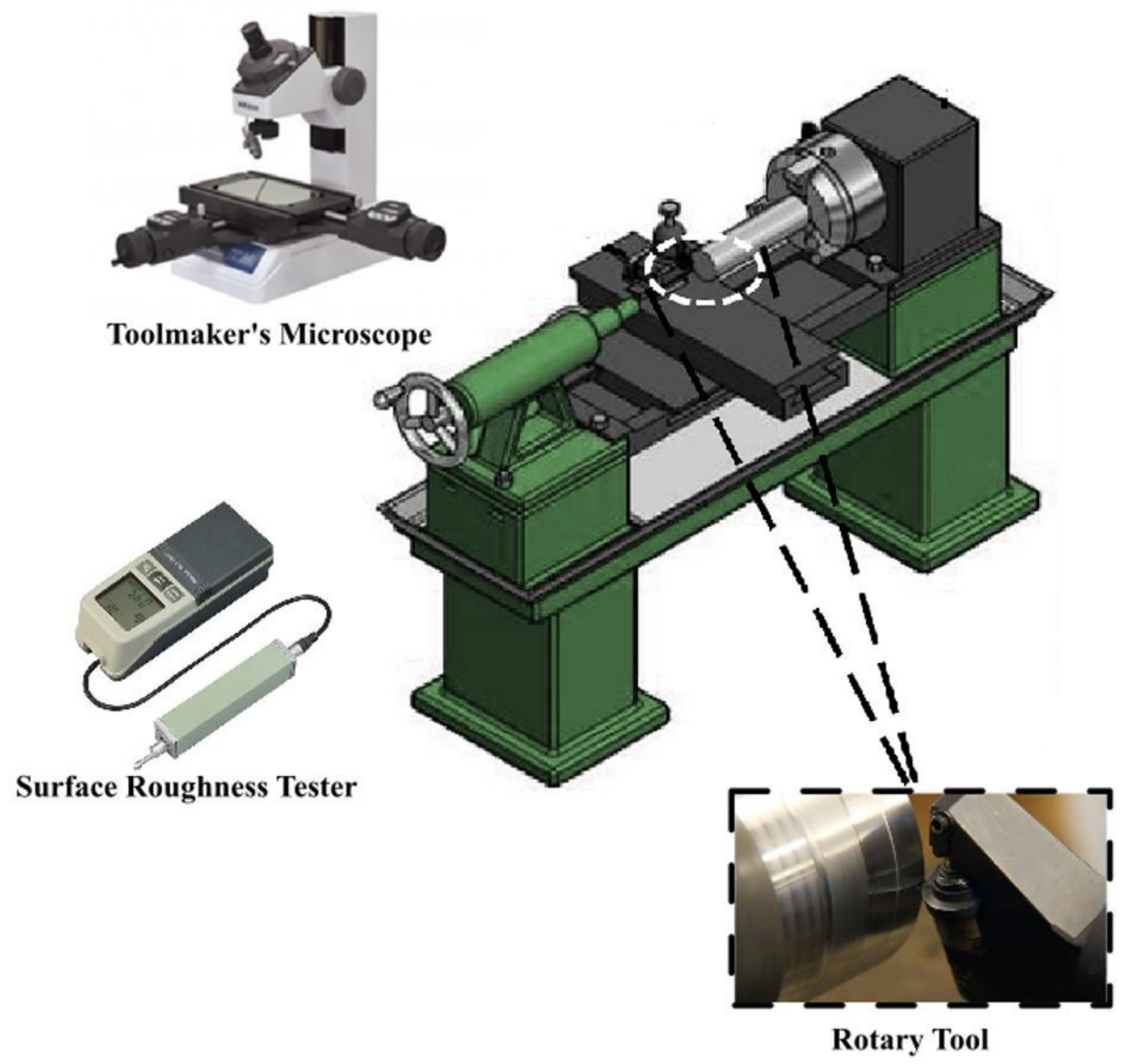

\section{Figure 4}

Experimental setup for the turning process using a self-propelled rotary tool

\begin{tabular}{|c|c|c|}
\hline $\begin{array}{l}\text { Cutting insert } \\
\text { - Round cutting insert with outer } \\
\text { diameter of } 27 \mathrm{~mm} \text { and made of } \\
\text { carbide } \\
\text { - Rake angle of }-5^{\circ} \text { and clearance } \\
\text { angle of } 5^{\circ}\end{array}$ & $\begin{array}{l}\text { Bar turning of AISI } 4140 \text { using } \\
\text { SPRT } \\
\text { The studied design variables are: } \\
\text { - Cutting speed } \\
\text { - } \quad \text { Feed rate } \\
\text { - } \quad \text { Inclination angle }\end{array}$ & $\begin{array}{l}\text { Machining performance } \\
\text { indicators }\end{array}$ \\
\hline
\end{tabular}

Figure 5

Flow chart of the experimental procedures 


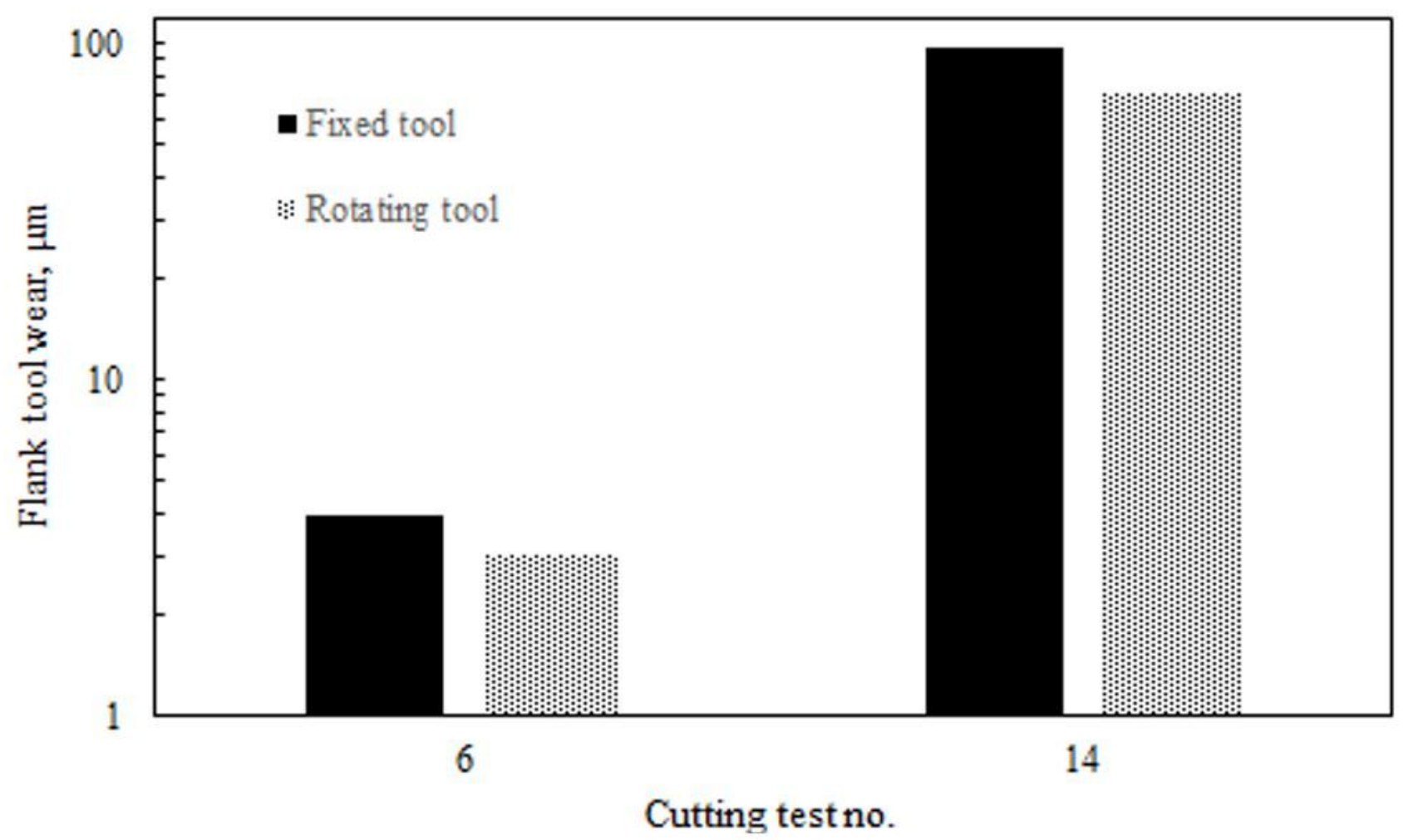

Figure 6

Tool wear results at worst and best scenarios for rotary tool versus fixed tool

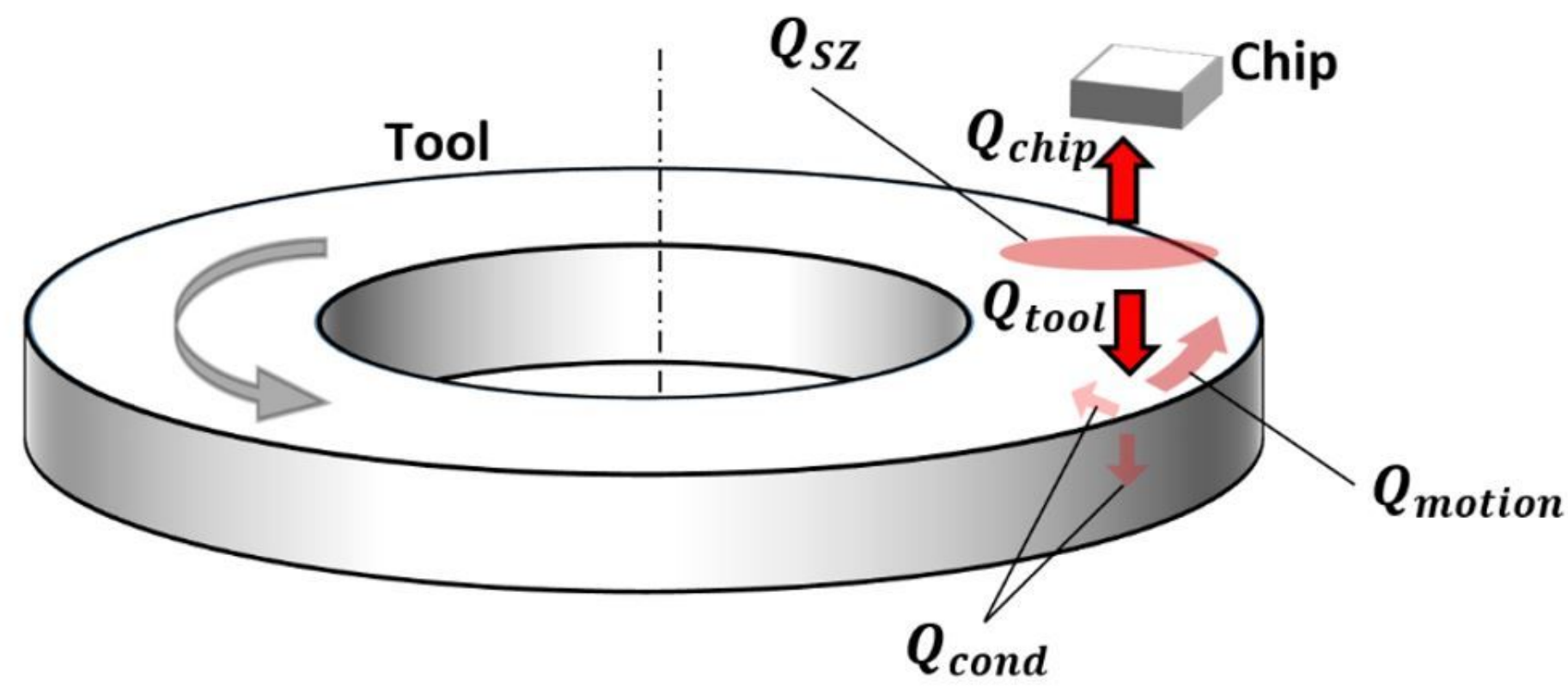

Figure 7

Schematic of machining using a rotary tool 


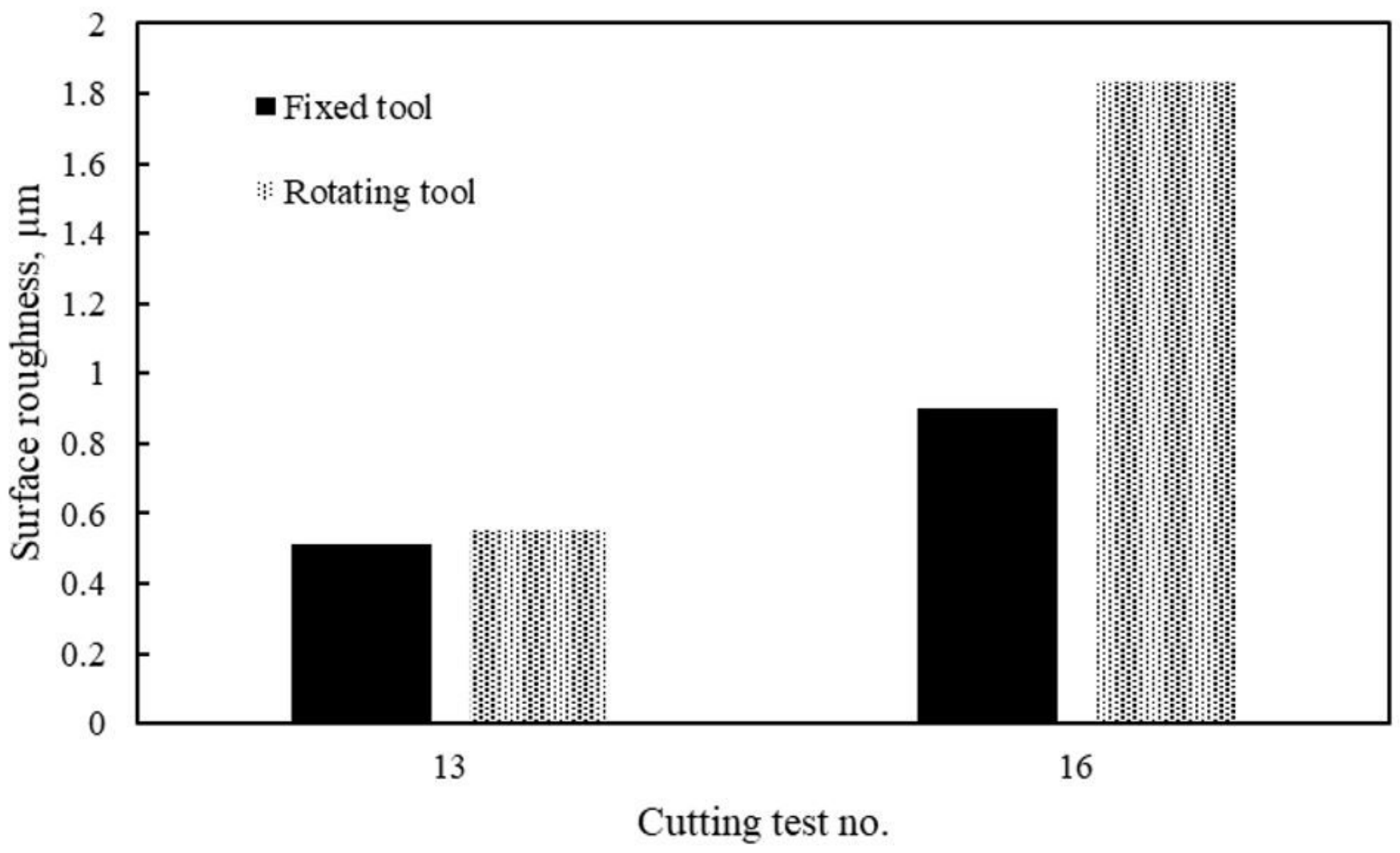

Figure 8

Average flank tool wear results at worst and best scenarios for rotary tool versus fixed tool 

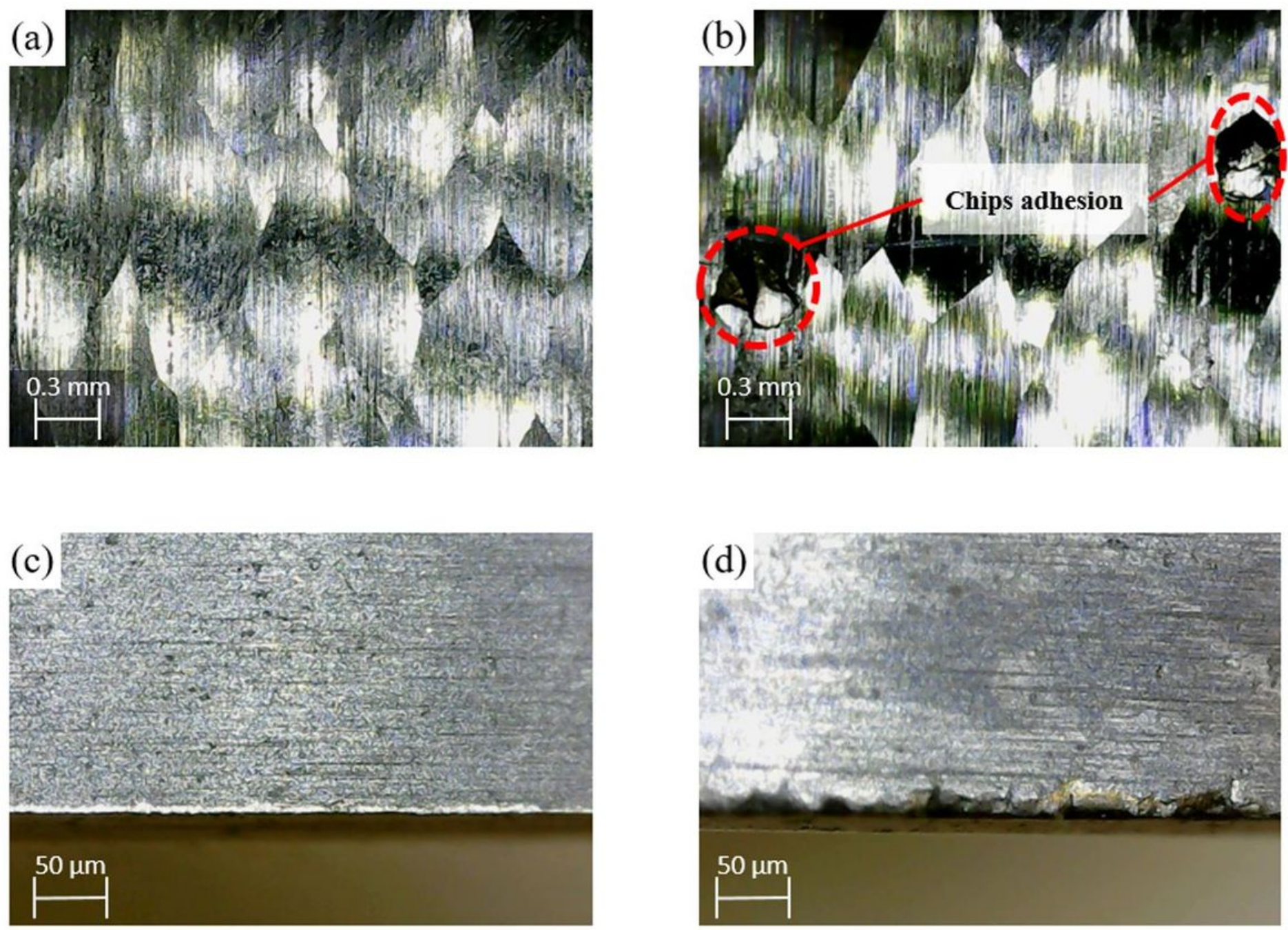

Figure 9

A Comparison between the finished surface and corresponding tool damage based on the tool inclination angle; (a, and $\mathrm{c})$ at $20^{\circ}$ and $(\mathrm{b}$, and $\mathrm{d})$ at $5^{\circ}$ 


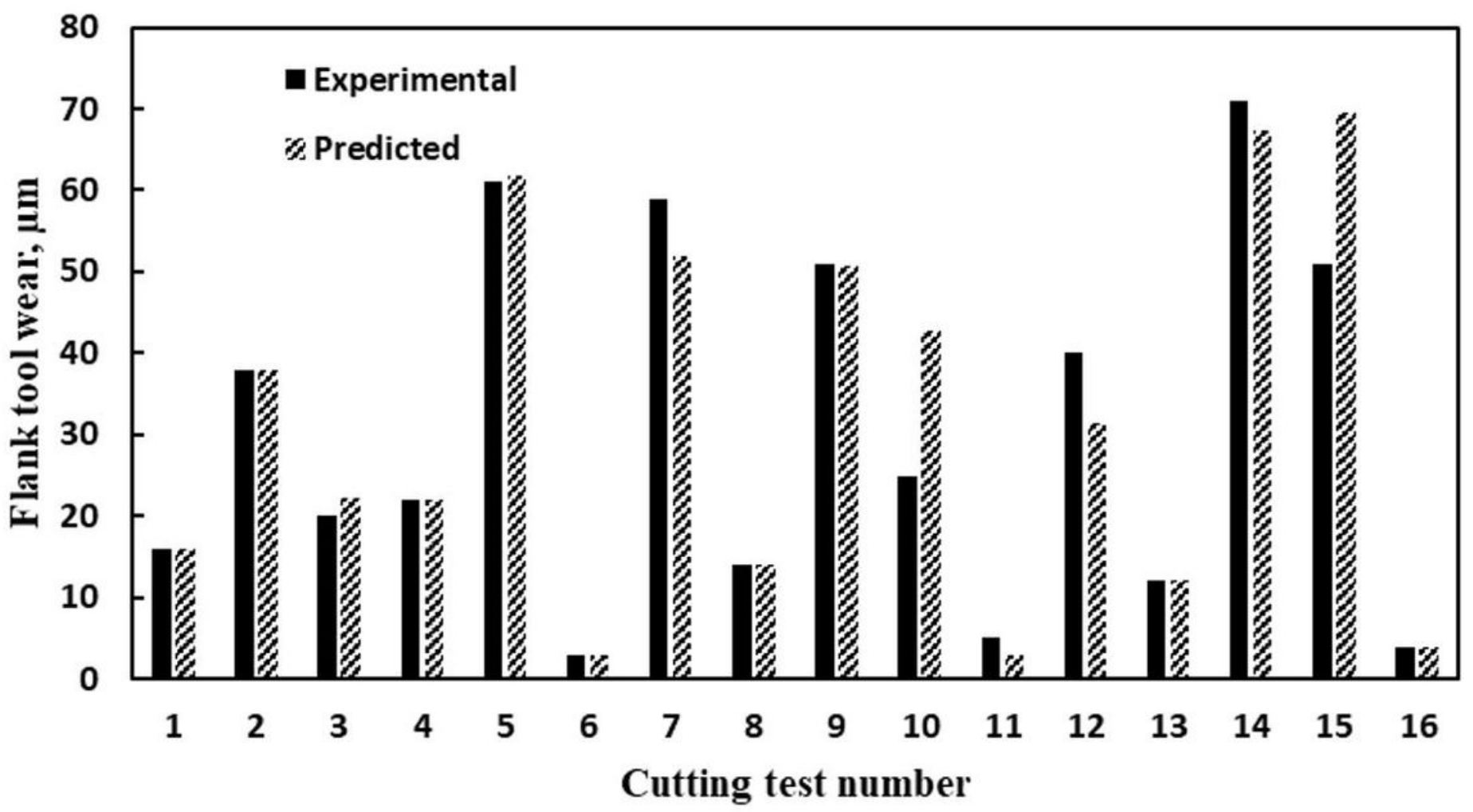

Figure 10

A Comparison between experimental and predicted flank tool wear

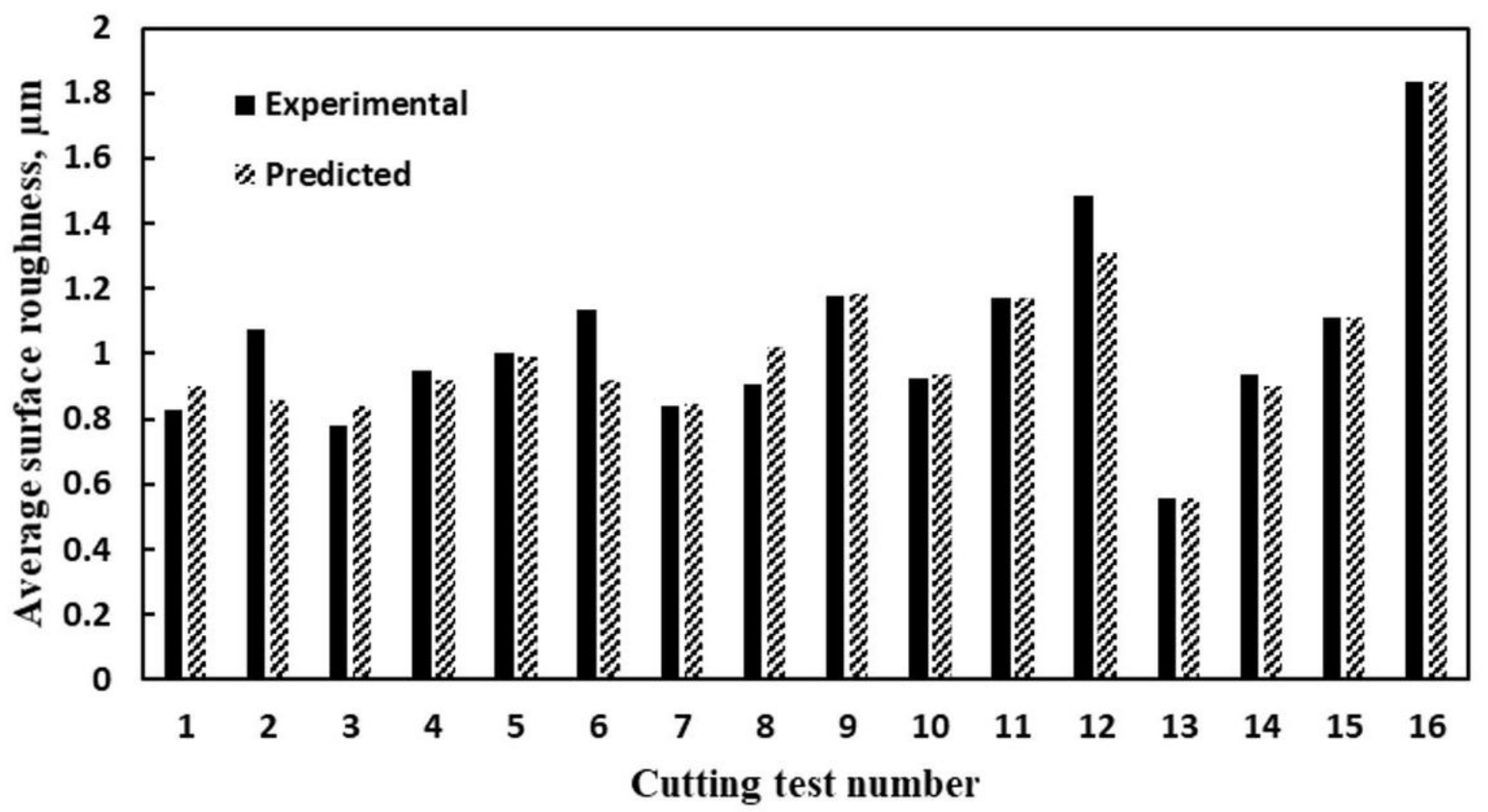

Figure 11 
A Comparison between experimental and predicted average surface roughness

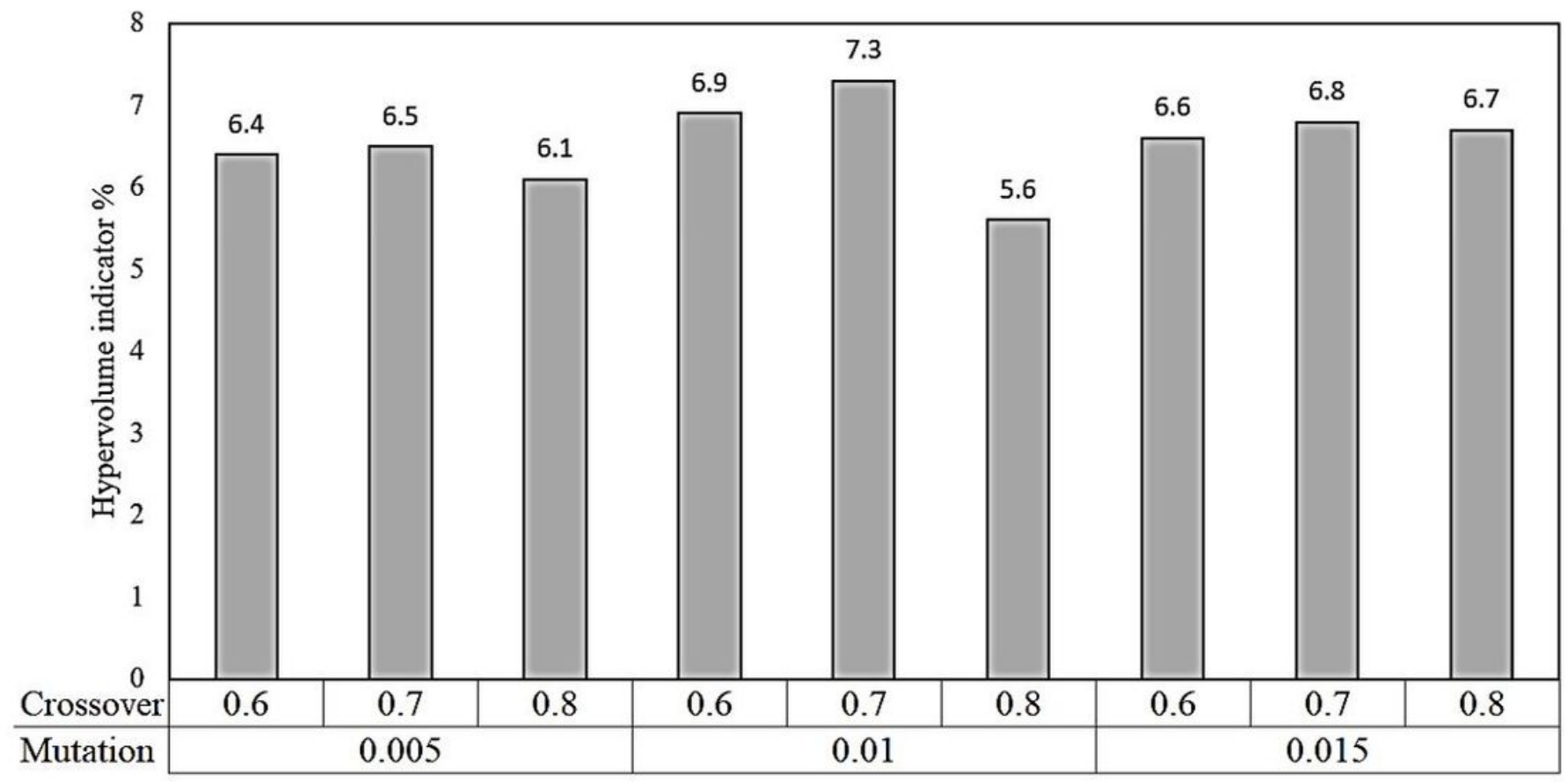

Figure 12

Hypervolume indicator for various values of mutation and crossover parameters

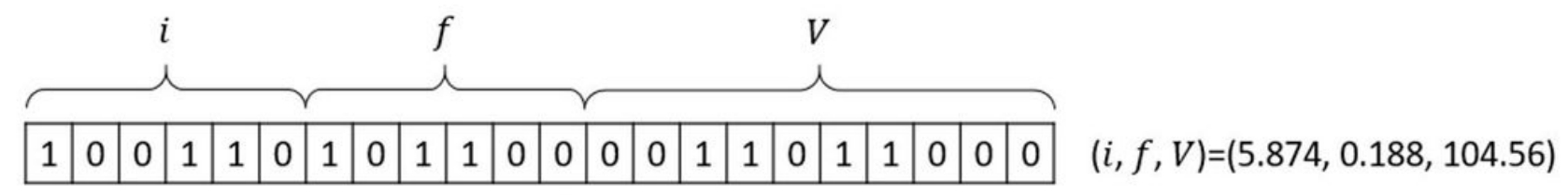

(a)

Parents

\begin{tabular}{|l|l|l|l|l|l|l|l|l|l|l|l|l|l|l|l|l|l|l|l|l|l|}
\hline 1 & 0 & 0 & 1 & 1 & 0 & 1 & 0 & 1 & 1 & 0 & 0 & 0 & 0 & 1 & 1 & 0 & 1 & 1 & 0 & 0 & 0 \\
\hline 1 & 1 & 0 & 1 & 0 & 0 & 1 & 1 & 0 & 0 & 1 & 0 & 1 & 1 & 1 & 0 & 1 & 1 & 1 & 0 & 1 & 0 \\
$(i, f, V)=(5.874,0.188,104.56)$ \\
$(i, f, V)=(16.96,0.2,222.64)$
\end{tabular}

Crossover

$\downarrow$

Offsprings

$$
\begin{array}{|l|l|l|l|l|l|l|l|l|l|l|l|l|l|l|l|l|l|l|l|l|l|}
\hline 1 & 0 & 0 & 1 & 0 & 0 & 1 & 1 & 0 & 0 & 1 & 0 & 1 & 1 & 1 & 0 & 0 & 1 & 1 & 0 & 0 & 0 \\
\hline 1 & 1 & 0 & 1 & 1 & 0 & 1 & 0 & 1 & 1 & 0 & 0 & 0 & 0 & 1 & 1 & 1 & 1 & 1 & 0 & 1 & 0 \\
(i, f, V)=(13.28,0.2,217.2) \\
(i, f, V)=(21.2,0.188,110)
\end{array}
$$

$\left.\right|_{\text {Mutation }}$

$$
\begin{array}{|l|l|l|l|l|l|l|l|l|l|l|l|l|l|l|l|l|l|l|l|l|l|}
\hline 1 & 0 & 0 & 1 & 0 & 0 & 1 & 1 & 0 & 0 & 1 & 0 & 1 & 1 & 1 & 0 & 0 & 1 & 1 & 0 & 0 & 0 \\
(i, f, V)=(13.28, \mathbf{0 . 2}, 217.2)
\end{array}
$$

Mutation

$$
\begin{array}{|l|l|l|l|l|l|l|l|l|l|l|l|l|l|l|l|l|l|l|l|l|l|}
\hline 1 & 0 & 0 & 1 & 0 & 0 & 0 & 1 & 0 & 0 & 1 & 0 & 1 & 1 & 1 & 0 & 0 & 1 & 1 & 0 & 0 & 0 \\
(i, f, V)=(13.28,0.136,217.2)
\end{array}
$$


Figure 13

(a) Individual's binary representation (genotype), (b) schematic of the crossover process, (c) schematic of the mutation process

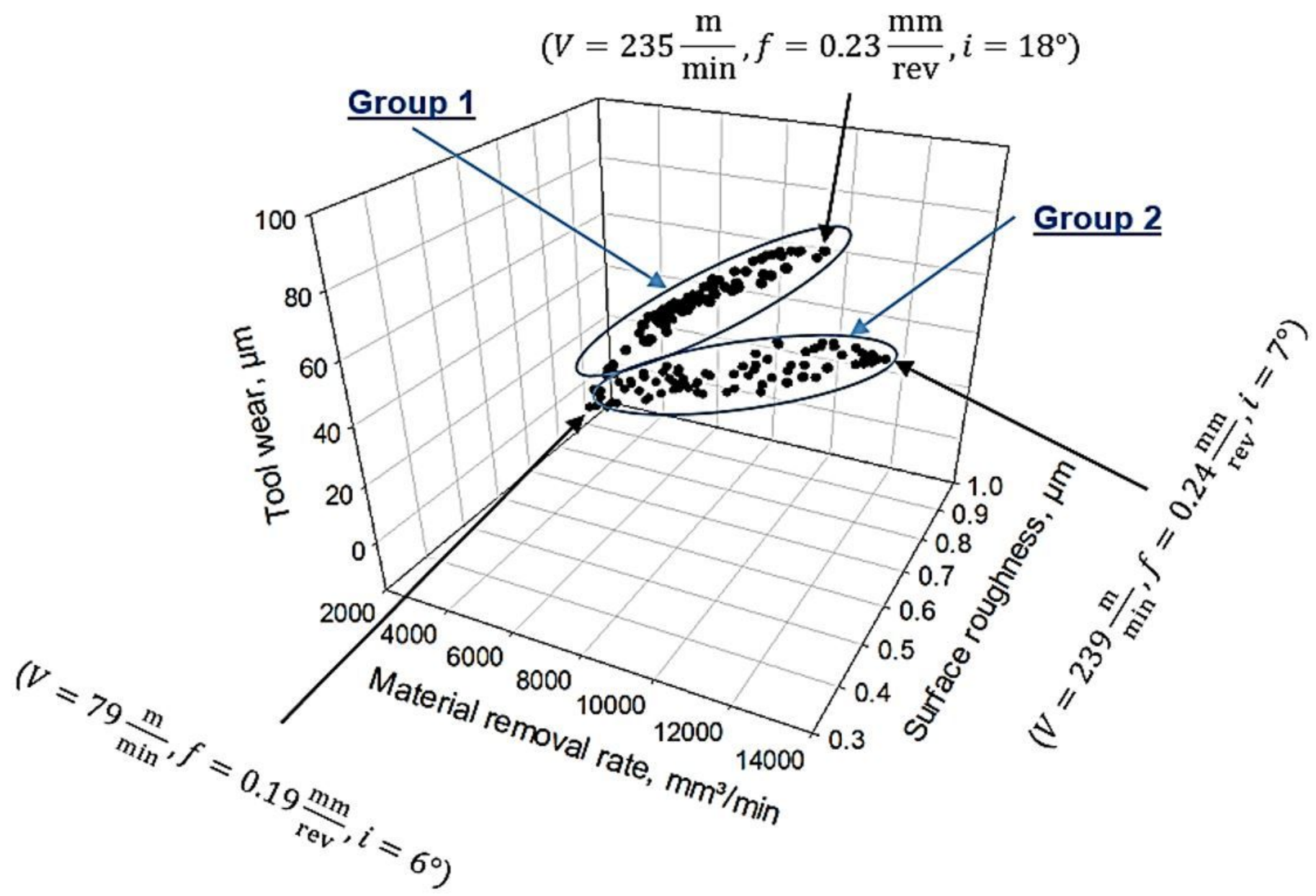

Figure 14

Pareto-front solutions

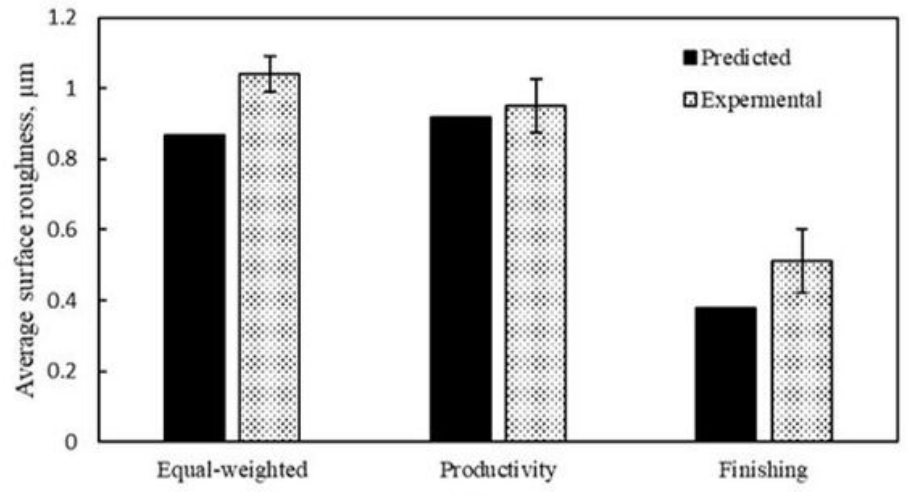

(a)

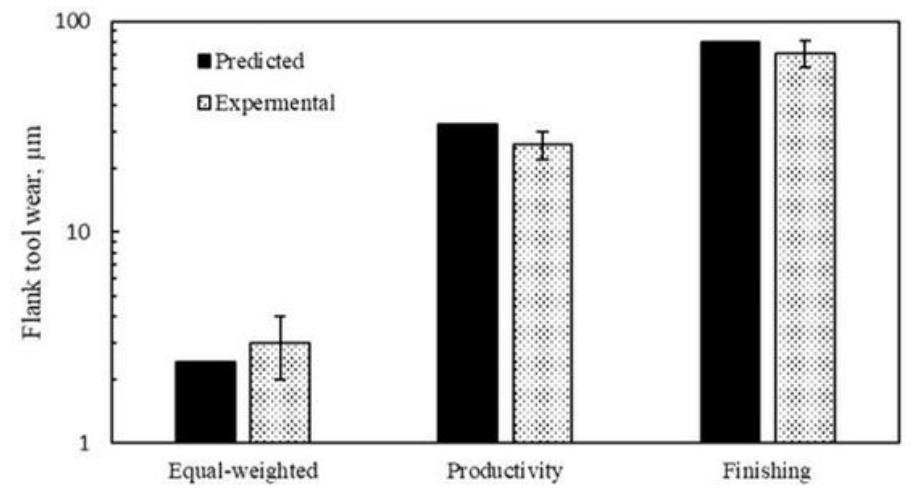

(b)

Figure 15 
Experimental validation of the optimized scenarios results; (a) Average surface roughness and (b) Flank tool wear 